\title{
LINGUODIDACTIC FUNDAMENTALS OF TEACHING STUDENTS HOW TO MAKE SENTENCES IN KARAKALPAK LANGUAGE LESSONS
}

\author{
A.S.Nauruzbaeva ${ }^{1}$ \\ Candidate of pedagogical Sciences, associate Professor, Department of pedagogy, Nukus state \\ pedagogical Institute \\ E-mail address: ayjan67@umail.uz \\ A.A.Embergenova ${ }^{2}$ \\ Teacher of Department of Primary Education, Nukus State Pedagogical Institute \\ E-mail address: eayzada1007@umail.uz.
}

\begin{abstract}
The relevance of the chosen topic is due to the need to pay attention to the lingua didactic foundations of teaching students how to make sentences in Karakalpak language lessons. According to scientists, the formation of grammatical skills in the process of mastering the Karakalpak language should occupy a strategic position, and practice has shown that students understand the meaning of words individually, but experience serious difficulties in combining them in a sentence since they have no idea how words should be combined to express a thought. Therefore, in order to form students' ability to build sentences for expressing thoughts, it is not enough to memorize typical phrases, it is necessary to teach children to build these phrases on their own.
\end{abstract}

Keywords: Affix, sentence, exercise, game, word form.

\section{INTRODUCTION}

Mastering the Karakalpak language opens up wide opportunities for expanding ideas about the features and originality of the Karakalpak language, ways of enriching it in the process of interacting with other languages. In addition, knowledge of the Karakalpak language makes it possible to join oral folk art, the works of modern writers and poets, to learn more deeply the history of Karakalpakstan, rich culture, customs and traditions of the people, their psychology, interests, aspirations, desires.

In the system of continuous education of the Republic of Karakalpakstan, the foundations for the formation of communication skills in the Karakalpak language are laid in the preschool years - at the most favourable time for mastering a second language.

For psychologists and educators have established that children 5-6 years old learn a second language much faster and better due to the fact that during this period they are distinguished by the flexibility of mind, freshness of perception, memory, showing the need and desire to communicate both with peers and with adults.

In the primary grades, the ability of children to acquire a second language is somewhat reduced, but this age is also considered favourable in this respect in comparison with the capabilities of high school students.

Observations of the process of teaching Russian-speaking primary school students in the Karakalpak language give grounds to assert that the level of speech development in the Karakalpak language does not meet the requirements of the State Educational Standard.

This circumstance is mainly expressed in the inability of children to build sentences on their own. The problem of teaching primary school students to construct sentences in the Karakalpak language has not yet been developed. Teachers most often orient children towards mastering words, memorizing phrases by memorizing them mechanically, which does not ensure the achievement of speech development.

In order for primary school students of schools with the Russian language of instruction to learn to communicate in the Karakalpak language, it is necessary to form their grammatical skills to construct sentences according to the laws of the grammar of the Karakalpak language. Teaching to speak the Karakalpak language presupposes the mastery of the linguistic material by students, the creation of the habit of using the Karakalpak language as a means of communication.

This means that the speaker must, first of all, no words, their grammatical forms, types of syntactic constructions, the laws of word formation, the norms of combining words and mastering the ability to use 
them in speech practice. In addition, to learn how to correctly articulate sounds specific to the Karakalpak language, to intonate a sentence, to make sentences in the volume that should be provided for by the state standard for the Karakalpak language for schools with the Russian language of instruction.

\section{THE PURPOSE AND OBJECTIVES OF THE WORK}

According to the deep conviction of scientists N.Urumbaev, A.Umarov, G. Zhumasheva, N.Barybina, V.A.Mireyeva and others, when teaching the ability to build grammatical structures of sentences, it is necessary to be based on the use of models.

At the same time, the tasks of working out the correct pronunciation of sounds, their combinations and whole words, the skills of using these words as part of speech samples should be comprehensively solved.

V. A. Artemov notes that when teaching oral speech, sometimes the emphasis is still placed on teaching "language models" instead of teaching "communication models" $(1,118)$ the ability to solve the definition of communicative tasks. However, in "models of communication", in some cases, there may be no new grammatical material.

In our opinion, "language models" should serve as a basis for "communication models", without which only communication models lose their learning effect. Since they are not always, they can serve skills in the preparation of sentences, on the contrary, they can be limited only to mastering the intonation corresponding to the communicative intention.

Using the same question and answer pattern, you can practice various communication models:

\# Apań qay jerde? Apam úyde.

\# A question requiring more information. Reply message.

* Apań úyde me ? Awa apam úyde.

* A question for clarification or confirmation.

* Apań úyde eken be ? Awa, apam úyde eken

A question that expresses feelings of surprise and frustration. Each question and answer contains a certain language and speech material, the language model and the communication model are combined.

\section{MAIN PART}

A speech model is a segment of an utterance that serves as a model for students to create their own texts/utterances / by analogy with this sample by making minor substitutions. This same model is also a communication model. (Several models of communication can be reproduced on the basis of the same speech model).

Teaching a monologue or dialogue by analogy has some similarities with substitution exercises: exercises in lexical, less often in grammatical substitution. Such exercises are widely covered in the methodological manual of R.A.Yuldashev (119).

Work on the speech model in most cases proceeds with the passive participation of children: when composing a text according to this model, the student writes or reads his own version, and sometimes tells, but this story is carried out on the basis of memorizing his text, which does not always help to form the skills of writing sentences.

Most importantly, the abundant speaking of each student in the target language is not provided. When drawing up a dialogue on this sample of the speech model, an exercise is performed in staging a staging. Replacement of words in the dialogue / for the most part, names are subject to replacement / is also performed in advance before the speech. Practice shows that the students who have learned. For example, children are offered the following speech model:
* Ájiniyaz úyde me?
\# Ájiniyaz shaqırıp jiberiń!
Ol sabaq tayarlap atır.
Awa Ájiniyaz úyde.
\# Ol ne islep atır?
Yaqshı, házir shaqıraman.

Pupils who act out the dialogue according to this speech model can change the words Ájiniyaz sabaq tayarlap atır. Children can enter the image of a wolf, bear, policeman, etc. In this case, grammatical substitution is also made.

* Ayzada úyde me? Awa Ayzada úyde.

* Ol ne islep atır? Ol chay demlep atır.

* Ayzadanı shaqırıp jiberiń! Yaqshı, házir shaqıraman.

Each student, according to this sample of dialogue, reproduces three replicas, but these replicas do not repeat the construction of the sentence: they are different in their structure. Thus, in the process of performing exercises in "creating" your utterance by analogy, in most cases, there is no purposeful work on constructing sentences. 
The dialogue sample is about clarifying whether the person being asked is at home. Therefore, it makes no sense to change the word uy to other words. It may be in the re-question: Ol qayaqta? Mektepte me? But in this case, the continuation of the dialogue disappears. That is why we consider the objections of the author of the developments L.Mirdzhalalova to be fair, who emphasizes:

"When composing questions and answers that are identical in structure, the use of dialogical texts is inconvenient: in order to build several questions and answers, it is necessary to perform the dialogue several times" (8.6).

That is why the author of these developments, following the methodological direction that was developed by R.A.Yuldashev, chose a sample of a sentence, a question and an answer, which represent a certain structure - a sentence construction, as a means of activating grammatical units.

It should be noted that not all questions and answers may have new grammatical material. So, for example, questions and answers like Bul ne? Bul kim? Mektep qanday?

Do not contain a new grammatical unit. By grammatical unit, we mean a grammatical means/affix / or a combination of two or more words according to certain grammatical rules. We believe that the above interrogative sentences cannot be an object of special study, but they can freely be included in the process of verbal communication, which should be preceded only by imitative exercises that contribute to the consolidation of intonation skills. If similar sentence constructions are taken to work on the interrogative particles $-b a$, $-b e,-p a$, - pe, $-m a$, - $m e$, then they also become a means of introducing these particles and become a model for a question and an answer, that is. a sentence construction containing a language learning unit.

Sample sentences are highlighted or selected based on the new grammatical units they contain. Their arrangement or distribution by years of study also takes into account the gradual complication of the grammatical form. For example: Dápter partada. Dápterler partadalarda. Dápterim partada. Dápterlerimiz partalarımızda. Dápter partada ma? etc.

Each subsequent sentence has a new grammatical material due to the complication of the morphological form of the word. So, the word dápter in the second clause takes the affix -ler, in the third - the affix -im, in the fourth - the affixes ler and -im. And the word partada in the second sentence is used with the affix - ler, two affixes in one word, in the third - with the affix -im. also two affixes in one word, but in the most complicated form, because the assimilation of the possessive affix by Russian children is very difficult, in the fourth sentence the form of the word is complicated by the presence of three affixes: -lar, -imiz, $-d a$.

Each change in the form of a word makes it unrecognizable, almost unfamiliar. That is why each step in the complication of the morphological form of a word is taken as a new grammatical unit of learning.

Scientists are deeply convinced that the formation of grammatical skills in the process of mastering the Karakalpak language should occupy a strategic position, and practice has shown that students understand the meaning of words separately, but experience serious difficulties in the process of combining them in a sentence since they have no idea how words should be combined to express a thought.

Therefore, in order to form students' ability to construct sentences for expressing thoughts, it is not enough to memorize typical phrases, it is necessary to teach children to build these phrases on their own.

Based on the foregoing, we tried to select such grammatical categories that would help:

* minimization of grammatical means;

\# distribution by classes, determination of the sequence of their location, - taking into account the possibilities of primary school students in mastering the grammatical means of the Karakalpak language;

* taking into account the influence of the native language in mastering these means.

The use / including pronunciation and spelling / of grammatical means of the Karakalpak language differs from the Uzbek grammatical means in that in the Karakalpak language the vowel harmony in a word in most cases determines the choice of the phonetic version of the affixes, which is completely absent in the Uzbek language. By this, we only want to emphasize the somewhat complexity of the study of the Karakalpak grammatical means, which can and should affect their minimization, because of the volume of grammatical materials increases due to knowledge, skills and abilities.

Determination of the volume and content of grammatical means to be studied in primary grades. In some respects, it is also related to the influence of the students' native language. This influence is specifically expressed in the similarities and differences in the linguistic facts of the Karakalpak and Russian languages. In order to clarify these similarities and differences, we briefly compared the grammatical means of the Karakalpak language with the materials of the Russian language.

In the Karakalpak language, the affixes attached to the stem / root / words are characterized by unambiguity, definiteness in their meaning, since usually each of them expresses only one grammatical 
meaning and each meaning is always expressed by the same affix.

In Russian, however, the root of a word does not always have an independent meaning. For example, if I go to take away the inflexion -y from the word, then this word/id / will not have a complete meaning.

N.A.Urumbaev emphasizes: "In the Karakalpak language, adding affixes can form a large number of words and forms from one root. So, the formation of various verb forms by adding / glueing / of the most diverse affixes is especially difficult" $"(2.6)$.

For example: Isle, islew, islen, isleniw, islet, isletiw, islettir, islettiriw, isles, islesiw, isletil, islengen, islep, isleme, islese, isler, islegenler, islegenlerińiz, isletilgenlerden etc.

Another feature of the Karakalpak language in comparison with Russian is the fact that when various affixes are attached, the stem or root of a word can almost always function without changes as an independent word (2.8).

When determining the content of teaching the Karakalpak language in the primary grades of schools with the Russian language of instruction, one should also take into account the fact that in the Karakalpak language in most cases there is no strict formal differentiation of parts of speech. For example, adjectives have no morphological indicators: biyik ag`ash/tall tree/, ag`ash qasıq/ wooden spoon/.

Therefore, if in the content of teaching the Russian language certain attention is paid to the study of formal features of adjectives, then adjectives are included in the content of teaching the Karakalpak language as ordinary vocabulary / as lexical material /.

Thus, taking into account the cases of the positive and negative influence of the native / Russian / language of students, the need for the development of speech in primary grades, it is possible to outline a circle of grammatical material that represents the minimum amount of knowledge, skills and abilities.

\section{\$ Plural affix.}

$\quad$ Safe affixes:-nı́, -niń, -dıń, -diń,-tıń, -tiń,-nı,-ni,-dı,-di,-tı,-ti,-n;-qa,-ga,-ke,-ga,-ge,-a,-e,na,-ne,-da,-de,-ta,-te,-nda,-nde,-nan,-nen,-dan,-den,-tan,-ten.

\# Postpositions:menen, benen, penen, ushın, ust, ast, ald, ish, sirt, jan, bas, tuwralı, jóninde, haqqında, qaray, qarap, taman, aylana, qarasmastan, baslap, qaraǵanda.

* Affixes of affiliation:-m,-im,-1m,-n,-1n,-in,-si,-s1,-I,-I,-miz,-miz,-imiz, -1mız,-niz,-nız,iniz,1n1z.

\# deyin, sheyin, shekem.

* Negative form of the verb:-ma,me,-pa,-pe,-ba,-be.

* Time forms: -ip,-1p,-p,-atır,-otır,-tur,-jur,-a,-e,-di,-d1,-tı,-ar,-er,-a,-jaq,-gan,-gen,-qan,-ken.

\# Personal conjugation affixes:-man,-men,-pan,-pen,-san,-sen,-miz,-miz,-piz,-p1z,-siz,-siz,-

m-n.

Infinitive:-iw,-1w,-w.

Ordinals :nshi,-inshi.

Collective numerals: -ew.

Affixes:-niki,-diki,-d1k1.

Interrogative particles:-ba,-pa,-ma.

Unions.

The use of affixes with homogeneous members of sentences. structures is unique.

These grammatical materials perform different functions and their role in the formation of sentence

\section{CONCLUSION}

The key problem of pedagogy and methodology is the construction of the teaching process on didactic principles, the essence of which is to determine the content, organizational forms and methods of teaching and education in accordance with their general laws.

G.P.Akhrorova, in her dissertation research (3.21), considers general pedagogical and particular methodological principles in two aspects: 1 / in the aspect of determining the content of teaching postpositional constructions of the Uzbek language and 2 / clarifying the methods of studying grammatical material both in the general direction and in organizing the lesson, giving preference to one of the types of speech activity. It is important to adhere to these principles in the selection, determination of the sequence of introduction, distribution by years of study. 


\section{REFERENCES}

[1] V.A.Artemov Psychology of teaching foreign languages. Moscow, 1969.

[2] N.A.Urumbaev Short course of comparative morphology of the Karakalpak and Russian languages N, 1991.

[3] G.P.Akhrorova Methods of studying postpositional constructions in Uzbek language lessons in schools with Russian language of instruction. Abstract of dissertation of candidate of sciences Tashkent, 1999.

[4] Jiyenbekovna, T. A. (2019). Formation of the system of increasing the qualification of teachers in Asian countries. European Journal of Research and Reflection in Educational Sciences: Special Issue 7 (10) pp 58-61.

[5] Irgashevich, D. A. (2020). Development of national network (tas-ix). ACADEMICIA: An International Multidisciplinary Research Journal, 10(5), 144-151. Article http://dx.doi.org/10.5958/2249-7137.2020.00254.2 